\title{
Effect of Slug Flow on Pipe Vibration in Horizontal Pipeline
}

\author{
ZHONG Xingfu' ${ }^{1}$ WU Yingxiang ${ }^{1}$ LI Donghui ${ }^{1}$ LI Zhibiao ${ }^{1}$ LI qiang ${ }^{2}$
}

\author{
1 Institute of Mechanics, Chinese Academy of Sciences No.15 Zhongguancun Road, Beijing 100080, China \\ 2 Jinghe Industry, Xi'an Shaanxi, Changqing Well Logging,China petroleum logging Co.LTD. 710201,China
}

\begin{abstract}
The vibration characteristics of the pipeline in gas liquid flow are investigated in this paper. The pipeline vibration which responds to pressure sensors and 3D laser measurement was analyzed. It shows that pipeline vibrations decrease in severe slug flow when gas flow rate increases and liquid flow rate keeps a constant. But when liquid flow rate increases and gas flow rate keeps a constant, at the first stage, the vibration increases and is up to a max amplitude, especially, in the slug flow. At the second stage, the amplitude of pipeline vibration decreases but the vibration frequency increases.
\end{abstract}

Key words: Slug flow Vibration Horizontal pipeline

\section{INTRODUTION}

The pipeline vibration can occur in petroleum, natural gas and chemical industry because of unsteady flow, the change of flow direction, pipe diameter, etc. This problem will affect safe running of pipeline severely if it is not handled well. Therefore, the pipe vibration arouses more and more people's attention. But nowadays, the study on it is mainly focused on the pipe vibration due to mechanical vibration source. However, there is a kind of pipelines in engineering with gas-liquid flow inside and whose both inlet and outlet are without pump and compressor, and they occur severe vibration. The reasons of this situation are too difficult to analyze.

Fluid vibration source in the pipeline has been analyzed by theoretical methods before ${ }^{[1]}$. Because of adopting some simplifications and assumptions, the results from these methods are only used to references. Generally, the vibration of the pipe system happens because of mechanical vibration, fluid vibration, vibration of themselves, earthquake and so on. Fluid vibration includes fluid pulsation, gas-liquid flow vibration, high-speed flow vibration and flow vibration outside the pipeline ${ }^{[2]}$. The first three kinds of fluid vibration are mainly analyzed in this paper.

The vibration of gas-liquid flow pipeline is studied by experiment in this paper. The main purpose of the study is to know the mechanism of this type of vibration, and to adopt reasonable steps to decrease the vibration. By means of changing gas-liquid flow-rate in experiment, the different flow patterns can be observed. After flowing steadily, the laser measurement is used to measure the displacement of the pipe. The influence of flow parameters on the pipeline vibration is analyzed, and the displacement and amplitude of the pipeline are computed. The experimental result indicates that the fluid flow plays an important role in pipe vibration response and must to be taken into consideration when designing the pipe. Besides, one of the main reasons to cause the pipeline vibrate is that flow pressure, velocity and density change periodically with time.

\section{EXPERIMENTAL SYSTEM AND METHOD}

The experiment is completed at the multiphase flow loop facility in IMECH. The pipeline of the facility is made of transparent organic glass. The flow patterns can be observed directly. The inner diameters of pipes are $50 \mathrm{~mm}$, and the length are $28 \mathrm{~m}$. The experimental mediums are air, water and oil. Gas and water are supplied by compressor and water tank separately. They go through respective flow meters and are mixed by T-type pipe in front of test pipe. At last, they are separated after flowing across the test section. Water returns to tank for re-use. Gas superficial velocity is $0 \sim 5 \mathrm{~m} / \mathrm{s}$, and liquid superficial velocity is adjustable within the scope from 0.2 to $1.2 \mathrm{~m} / \mathrm{s}$. 
FIGURE 1 is the sketch of test section. Fig la is the photo of section $A C$ and is enlarged in fig $\mathrm{lb}$. The distance from upper stream A to downstream B of horizontal section is $1 \mathrm{~m}$. The distance from section $A$ to inlet is $22 \mathrm{~m}$ and $C$ to outlet is $5 \mathrm{~m}$. Three pressure sensors are installed on both section $A$ and $C$, in order to obtain the pressure signals and differential pressure signals.

Point $B$ is the measurement point of pipe vibration that is got from the middle point of section $A C$ and jointed rigidly with $A C$. Pipeline's vibration in the $X, Y$ and $Z$ direction when two-phase fluid flows from $A$ to $C$ is obtained by measuring the vibration displacement of point $\mathrm{B}$ in these three directions. This displacement is measured by optoNCDT laser instrument, which resolution is $20 \mu \mathrm{m}$ and accuracy $0.01 \% \mathrm{FSO}$.

Different flow pattems are obtained in the pipeline by changing given flow rate of gas-liquid. They can be observed and recorded after flow is steady. At the same time, the signals of pressure, differential pressure and vibration distance of the pipeline are recorded, too. All the values about signals are got from DAQP acquisition system which sample frequency is $50 \mathrm{~Hz}$. The process of the experiment is that gas flow rate $(10,50,100,200$, $300,400$, unit: $\% 25 \mathrm{l} / \mathrm{min})$ increases gradually under the condition of constant liquid flow rate $(4,6,10,20$, $40,60,70$, unit: $\% 25 \mathrm{~m}^{3} / \mathrm{h}$ ), and then the data are gathered and recorded. The units of measurement in this paper are the ones of the meters used in the experiment. Without special explanation, the unit of liquid flow rate $w$ is $\% 25 \mathrm{~m}^{\wedge} 3 / \mathrm{h}$, and the liquid flow rate is $\% 25 \mathrm{l} / \mathrm{min}$.

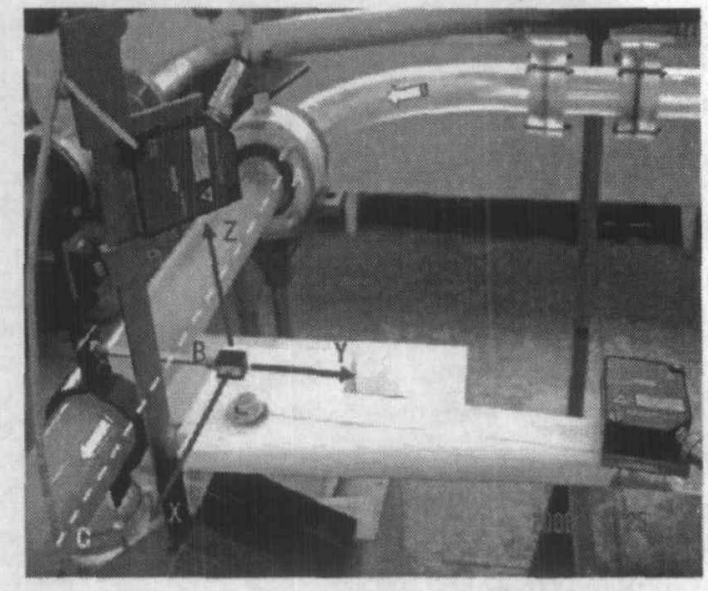

a、 The photo of experimental pipeline and test section $\mathrm{AC}$

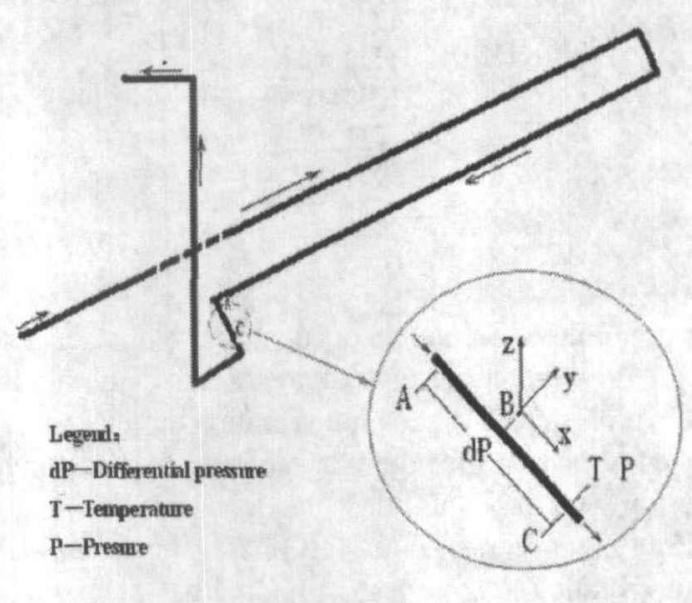

b、 A sketch map of test section AC

FIGURE 1. The experimental flow pipeline

\section{THE ANALYSIS OF FLOW PATTERNS IN THE PIPE}

During the two-phase flow, flow patterns are changed with phase velocity, density, viscosity and surface tension of the individual phase. It not only affects flow characteristics, mass and heat transfer, and vibration characteristics, but also affects the system's dependability, safety and efficiency. It is wellknown that fluid pulsation appears when pipe flow's parameters such as pressure, velocity and density change periodically with time. Slug flow pattern is a kind of typical fluid pulsation. It's one of the main reasons that arouse the pipe and the attached instruments vibrate.

In order to analyze the vibration caused by the fluid flow in pipeline, first of all, the flow patterns are observed and recorded carefully. FIGURE.2 gives out the flow patterns and the extension of experimental parameters. Its horizontal axis is liquid flow rate, and vertical axis is gas flow rate. The flow patterns which can be seen during the experiment are bubble flow, slug flow, stratified flow and wavy flow.

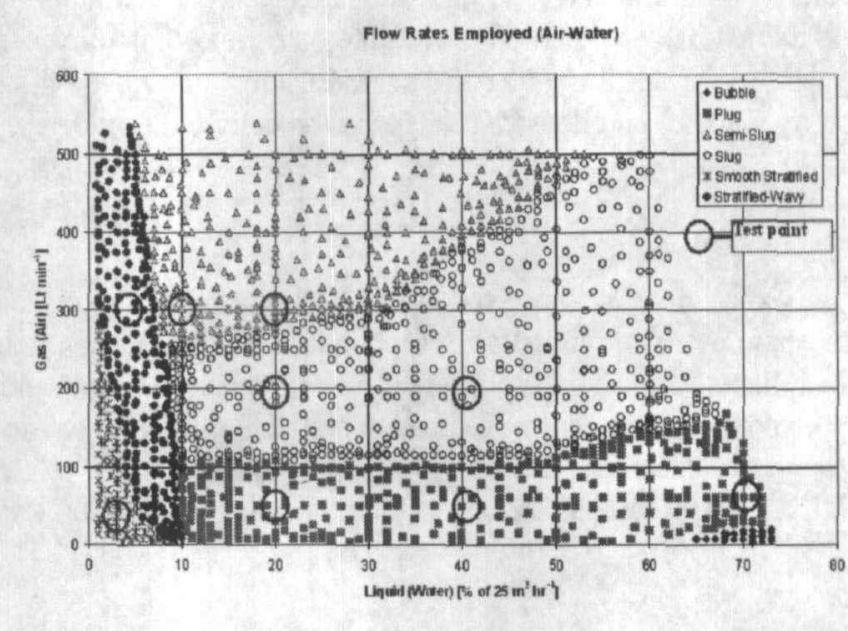

FIGURE 2. Flow pattern in horizontal pipeline(ID=50mm) 
According to this figure, the needed flow patterns can be obtained manually. Due to gravity, gas is mainly at the top of the pipe, and liquid is at the bottom. Usually, gas-liquid two-phase horizontal flow is defined into following flow patterns: bubble flow, slug flow, stratified flow and wavy flow.

Flow pattems not only can be observed directly, but also can be analyzed from measured signals. The fluctuations of pressure drop are different under different flow patterns, so pressure changes reflects the flowing situation at certain degree. For example, , pressure fluctuation is large when slug flow happens. FlGURE.3 is fluctuation response of vibration displacement and differential pressure in $Y, Z$ direction which are simultaneously measured when $w=4, g=50$. Flow patterns, pressure and pipe vibration are corresponding to each other. To this slug flow, the length of gas slug is about $9-13 \mathrm{~m}$ and the tail is long, while the water slug is short. The frequency of the gas slugs' appearance is approximately $0.14 \mathrm{~Hz}$, which agrees with the PSD analysis result very well. The length of water slug is $3-4 \mathrm{~m}$, in which there are little gas bubbles. When there is no gas or liquid slug, and the water level is at the $2 / 5$ position of the pipe, a part of water flows back after a large water slug passes test section. FIGURE. $3 \mathrm{~b}$ shows an integrated slug flow that the liquid slug section $\mathrm{AC}$ and the gas slug section. Here the liquid slug section $\mathrm{AC}$ is analyzed first, then the gas slug $\mathrm{CE}$.

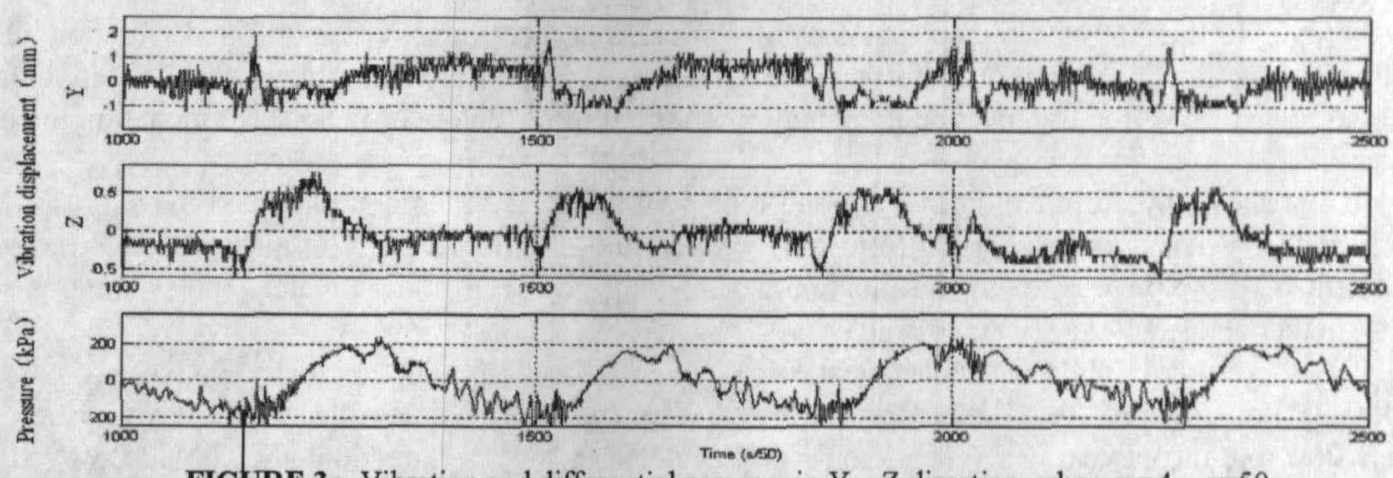

FIGURE 3a Vibration and differential pressure in $Y, Z$ direction when $w=4, g=50$

X-axis: Time(1/50 s), Y-axis: Vibration displacement(mm)

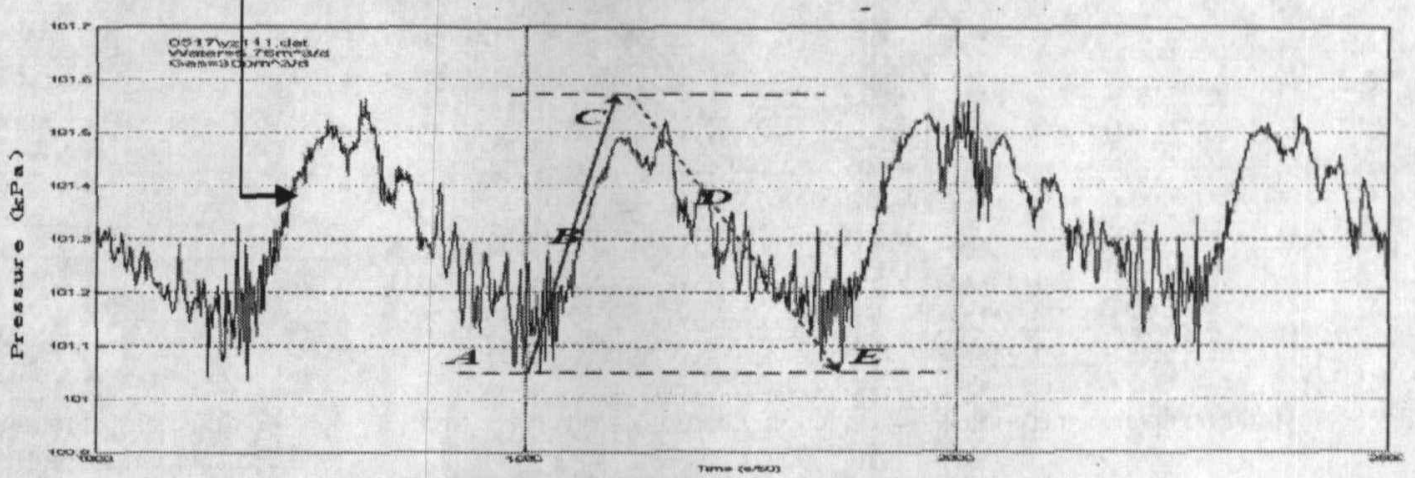

FIGURE 3b Typical pressure fluctuate $(w=4, g=50)$

$\mathrm{X}$-axis: Time(1/50 s), Y-axis: Pressure $(\mathrm{kPa})$

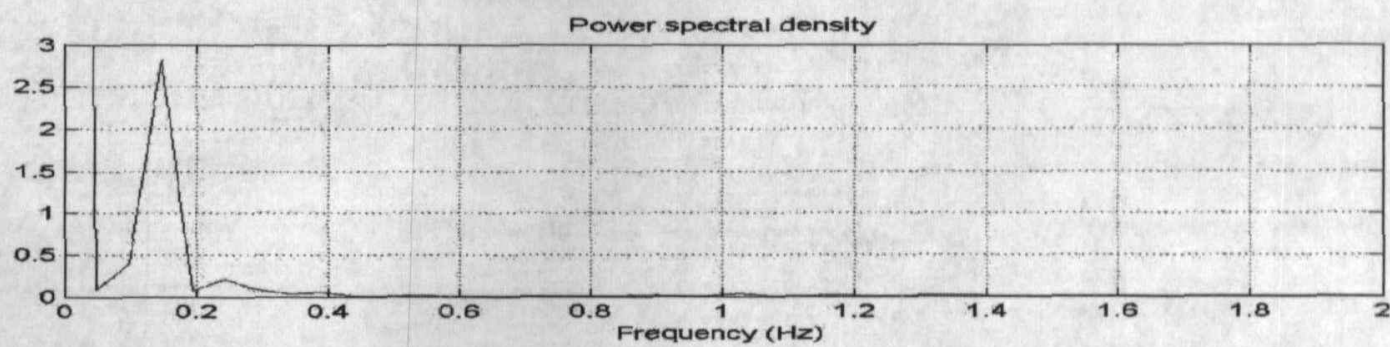

FIGURE 3c The PSD of pressure fluctuate $(\mathrm{f}=0.14 \mathrm{~Hz}, \mathrm{w}=4, \mathrm{~g}=50) \mathrm{X}$-axis: Frequency $(\mathrm{Hz}), \mathrm{Y}$-axis:

Energy 
FIGURE 3. Vibration displacement and differential pressure in $Y, Z$ direction in slug flow $(w=4, g=50)$

The point $A$ of section $A C$ in FIGURE $3 b$ is the head of a liquid slug and point $C$ is tail. When the liquid slug reach the pressure sensor, pressure rapidly increases from point $A$ (low value) to point $C$ (high value). The section $\mathrm{BC}$ is the pure liquid slug, of which pressure fluctuation is smaller than the one of section $\mathrm{AB}$. After the liquid slug passes away the test pipe, the pressure reduce and the flow come into stage of gas slug.

The point $C$ of section CE in FIGURE $3 b$ is the front of the gas slug and point $E$ is tail. When the gas slug reaches the pressure sensor, pressure decreases from point $\mathrm{C}$ (high value) to point $\mathrm{E}$ (low value). liquid holdup is different at different place of the same gas slug, the pressure fluctuation in gas slug's is larger than the liquid slug's. During the process of gas slug flow CE in Fig $3 \mathrm{~b}$, the pressure fluctuation is always large, and descending of pressure dorp is slow relatively. Until the gas slug CE has passed the pipeline, the pressure begins to ascend, and the flow comes into the next stage.

\section{ANALYSIS OF HORIZONTAL PIPE VIBRATION CAUSE BY TWO-PHASE FLOW}

The vibration of the pipe system happens generally because of mechanical vibration, fluid vibration, vibration of themselves and earthquake and so on. Fluid vibration includes fluid pulsation, gas-liquid flow vibration, high-speed flow vibration and flow vibration outside the pipeline. The first three factors of them are principal in the analysis of this paper.

FIGURE3a shows the differential pressure and pipe's vibration in $Y, Z$ direction when the slug flow occurs. It can be seen that when liquid slug got to the test point (liquid slug is section AC in FIGURE.3b), the vibration displacement of the pipe was up to the maximum. Gas slug has little effect on the pipe's vibration. Vibration becomes smaller and smaller after liquid slug passes.

FIGURE 4 gives vibration's displacement in $\mathrm{X}, \mathrm{Y}, \mathrm{Z}$ direction with gradually increasing gas flow rate $(g=50,100,300)$ on condition that liquid flow rate is constant $(w=4)$. It indicates that the pipe's vibration decreases when gas flow rate increases. Fig. 5 is vibration's displacement in $X, Y, Z$ direction when liquid flow rate increases $(w=4,6,20,40,70)$ under condition of constant gas flow rate $(g=50)$. The pipe's vibration becomes severe gradually as the liquid flow rate goes up, and there is the max amplitude. Then the amplitude of pipeline comes down, but the frequency increase.

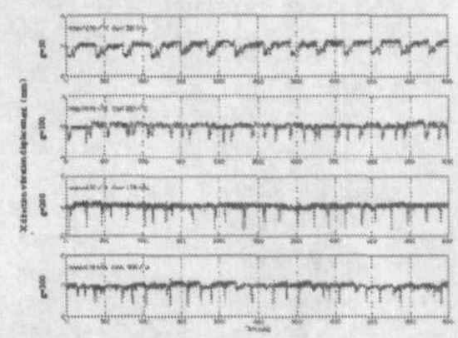

$\mathrm{X}$ direction vibration displacement(mm)

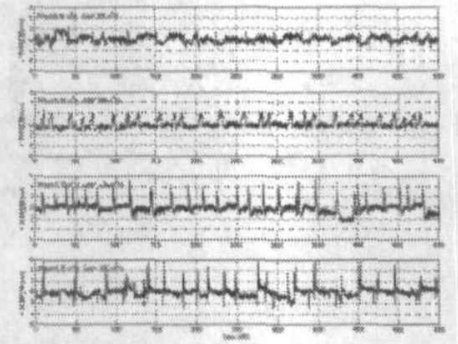

$\mathrm{Y}$ direction vibration displacement(mm)

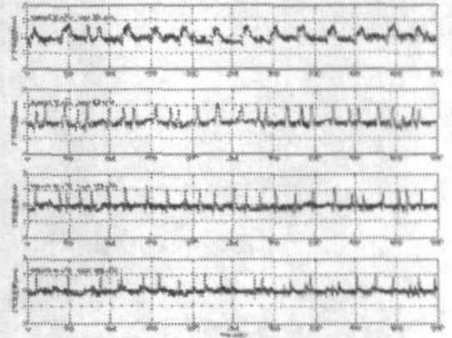

$\mathrm{Z}$ direction vibration displacement(mm)

FIGURE 4. The 3D vibrations of pipeline in horizontal slugging flow when gas flow rate increase and liquid flow rate keep a constant $(w=4, g=50,100,200,300), X$-axis: Time(1/50 s), Y-axis: Vibration displacement(mm)

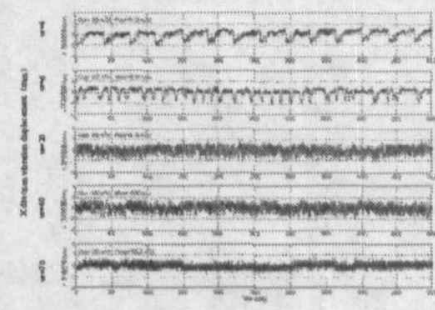

$\mathrm{X}$ direction vibration displacement $(\mathrm{mm})$

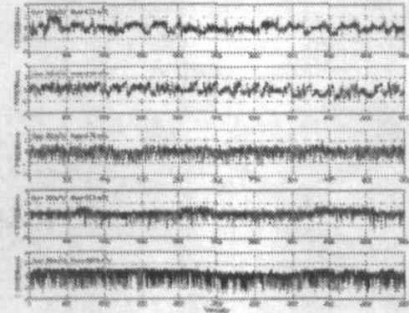

$\mathrm{Y}$ direction vibration displacement( $\mathrm{mm})$

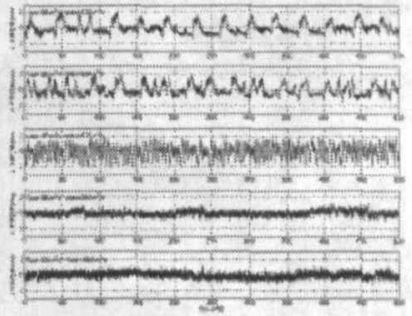

$\mathrm{Z}$ direction vibration displacement(mm)

FIGURE 5. The 3D vibrations of pipeline in horizontal slugging flow when the liquid flow rate increase and gas flow rate 
keep a constant( $(\mathrm{g}=50, \mathrm{w}=4,6,20,40,70), \mathrm{X}$-axis: Time( $1 / 50 \mathrm{~s}), \mathrm{Y}$-axis: Vibration displacement(mm)

\section{CONCLUTION}

Gas-liquid two-phase flow in pipeline is common in the petroleum chemical industry equipment. In the process of gas-liquid flowing, some pipes vibrate severely owing to the changes of flow parameters, pipe's construction and arranging ways. Feebleness pipe vibrations could not damage the equipment, but more intense vibration may cause pipes' construction and the equipments at upper stream and downstream harmful, even to make them stop running. Through experimental researches on gas-liquid two-phase flow in the horizontal pipe, some experimental results were obtained, but the mechanism is not further analyzed that the fluid flowing parameters affect pipe's vibration.

Initial experimental results indicate that the pipe vibration gets weaker and weaker when liquid flow rate keeps constant, and gas flow rate increases. Whereas, when gas flow rate is constant, the vibration becomes more violent gradually with liquid flow rate increasing, and then the vibration has the max amplitude. Subsequently the amplitude of pipe's vibration decreases, but vibration's frequency increases. Seen from the measuring results, flow parameters such as flow pattem and pressure respond to pipeline's vibration. The relationship between these parameters is await to be further analyzed.

\section{ACKNOWLEDGEMENTS}

The author is grateful to Simon Philip (School of Chemical Engineering and Analytical Science, The University of Manchester Manchester M60 1QD, United Kingdom) and Dr. Jy XU for their flow pattern experimental used in this paper.

\section{REFERENCES}

1. Tan ping, FU xingjun et al. Study on Vibration of Conveying Water Piping System in Power Plant, TURBINE TECHNOLGY, Vol.46, No.2, 2004.

2. Zhang Duqing, Zhang Guangcheng et al. Treatments\& Reasons for Vibration of the Pipe in Power Plants, SHANDONG DIANLI JSHU, Shan Dong Power Technology. Vol.47, No.1, 2006. 